\title{
ПАДЕНИЕ АДАПТИВНОЙ ЭФФЕКТИВНОСТИ РОССИЙСКОЙ ЭКОНОМИКИ - ИНСТИТУЦИОНАЛЬНАЯ ЛОВУШКА ИЛИ ДИСФУНКЦИОНАЛЬНОЕ СОСТОЯНИЕ?
}

\begin{abstract}
АНнотАция. На фоне различных внешних воздействий и шоков мы становимся свидетелями все ухудшающейся ситуации в России. Эксперты все чаще говорят о структурном экономическом и институциональном кризисе, возрастании неопределенности с одновременным снижением адаптивных возможностей национальной системы, неизбежности падения всех параметров как в экономической, так и в социальных сферах. Неспособность перебороть негативные тенденции, используя традиционный неоклассическо-либеральный инструментарий, обращает наше внимание на институциональные подходы, в частности на теории институциональных ловушек и дисфункциональности институтов. Оба подхода, имея массу схожих черт, тем не менее расходятся по ряду вопросов. Подобные различия представляют собой не только теоретико-методологический интерес, но и позволяют взглянуть на проблему повышения адаптивной эффективности под новым углом, сформировав ряд рекомендаций.
\end{abstract}

кЛюЧЕВЫЕ СЛОВА. Институциональная ловушка; адаптивная эффективность; дисфункция; неопределенность.

ИНФОРМАЦИЯ О СТАТЬЕ. Дата поступления 28 января 2016 г.; дата принятия к печати 26 февраля 2016 г.; дата онлайн-размещения 23 марта 2016 г.

V. A. Rudyakov

Baikal State University,

Irkutsk, Russian Federation

\section{DECLINE OF ADAPTIVE EFFICIENCY OF RUSSIAN ECONOMY - IS IT AN INSTITUTIONAL TRAP OR A DYSFUNCTIONAL STATE?}

\begin{abstract}
Against the background of various external impacts and shocks we are witnessing ever more aggravating situation in Russia. Experts are talking increasingly frequently about the structural economic and institutional crisis, about increasing of uncertainty with instantaneous decreasing of adaptive possibilities of the national system, inevitable decline of all parameters both in economic and social spheres. The inability to overcome the negative tendencies using traditional neo-classical-liberal instrumentarium attracts our attention to institutional approaches, particularly, to the theory of institutional traps and dysfunctionality of institutions. While having a great amount of similar features, nevertheless the both approaches differ in a number of issues. Such differences present not only a theoretical and methodological interest but also allow to have a look at the problem of increasing the adaptive efficiency from a new prospective by developing a number of recommendations.

KEYWORDS. Institutional trap; adaptive efficiency; dysfunction; uncertainty.

ARTICLE INFO. Received January 28, 2016; accepted February 26, 2016; available online March 23, 2016.
\end{abstract}

В современных условиях особо важным «качеством» национальных экономик становится их способность адаптироваться к факторам и проявлениям неопределенности. Базовая характеристика факторов, способствующих повышению адаптив-

\section{Baikal Research Journal}


ной эффективности, дана нобелевским лауреатом Д. Нортом. С позиций указанного автора, при анализе факторов, влияющих на адаптивную эффективность, надо различать макро- и микроуровень.

Макрофакторы Д. Норт [1, с. 106-107] делит на две группы:

1. Общая институциональная структура, которая играет ключевую роль в том, в какой степени общество и экономика поощряют эксперименты и инновации. Стимулы, встроенные в общую институциональную структуру, задают направления процессу обучения и развитию совокупности знаний, и подталкивают индивидов, принимающих решения, к постепенному изменению институциональной системы по сравнению с тем ее состоянием, с которым они (индивиды) имели дело первоначально.

2. Наличие совокупности правил, которые позволяют экономике освобождаться от «проигравших» экономических организаций. В данном случае эффективная структура правил не только вознаграждает за успех, но и накладывает вето на возможность выживания плохо приспособленных частей общественной организационной структуры, т. е. эффективные правила прекращают неудачные усилия и поддерживают удачные усилия. $К$ подобным правилам Д. Норт относит:

- конкуренцию - особо отмечая, что при слабой конкуренции, либо в связи с «беспорядочными» конкурентными сигналами, «адаптация экономических агентов будет происходить медленно или в неправильном направлении, и результаты конкуренции, предусматриваемые классической теорией, не будут проявляться в течение очень долгого времени" [1, с. 43];

- децентрализованное принятие решений, позволяет обществу рассматривать и исследовать несколько альтернативных способов решений и выбрать лучшее;

- четко определенные контракты на права собственности, обеспечивающие стимул к поиску и созданию новых технологий и продвижению на рынке результатов научно-технического прогресса.

Что касается микроуровня, то Д. Норт отмечает, что «предприниматели могут направить свои таланты или знания на поиск выгодных возможностей для получения потенциального выигрыша... әффективность организации зависит от возможности воспринять и реализовать такие возможности» [Там же, с. 113].

Как мы видим, среди макроэкономических факторов особую роль играют институты. При этом адаптивно эффективные институты по Д. Норту должны обеспечить стимулы к обучению и к знаниям, стимулировать инновации, поощрять экономических агентов, склонных к риску и имеющих предпринимательскую способность. Таким образом, адаптивная эффективность институтов определяется их гибкостью, возможностью воспринимать изменения, выживать и развиваться в условиях происходящих изменений.

Соответственно, устойчиво неэффективные и негибкие институты, носящие самоподдерживающийся характер, не просто снижают адаптивную эффективность, но и могут разрушить саму возможность развития (и, как крайний случай, существования) макроэкономической системы. Как мы понимаем, речь идет об негативной «зависимости от предшествующего развития» в институциональной сфере. Подобная зависимость получила в современной литературе название институциональной ловушки.

Наличие институциональных ловушек, очевидно, является наиболее ярким свидетельством провала адаптивных возможностей национальной системы.

Причин возникновения институциональных ловушек множество. В. М. Полтерович, автор данного понятия, основными из них видит «неподготовленность реформ в сочетании со слишком быстрым темпом реформирования, нерациональное манипулирование макроэкономическими инструментами» [2, с. 12].

\section{Baikal Research Journal}


В свою очередь, О. С. Сухарев [3, с. 68] выделяет следующие основания снижения качества институтов:

1. Неуправляемость институциональных изменений (неэффективный план).

2. Соперничество между различными институтами, а также институтами и агентами.

3. Высокая скорость институциональных изменений, введения новых институтов.

4. Экономическая политика, снижающая качество институциональной системы за счет воздействия на мотивы поведения экономических агентов (принуждение, денежное вознаграждение, отождествление, приспособление).

Согласно В. А. Беренделевой основная проблема состоит в том, что в российском обществе укоренилась модель, ориентированная на достижение краткосрочных интересов [4]. Подобной точки зрения придерживаются и А. С. Абелян с Ф. Е. Аксаевым, отмечая, «что в условиях неопределенности и нестабильности следование долгосрочной модели приносит убытки, а прибыльные краткосрочные сделки убеждают экономических агентов отказаться от модели, основанной на долгосрочных интересах» [5, с. 17].

Ю. Лысенко и А. Стрижак отмечают значимость гипертрофированности оппортунистического поведения. «Как изначально негативный феномен, способный к деструкции социально-экономических отношений, оппортунистическое поведение формирует квазиорганизации и неэффективные нормы, которые стабилизируются и укореняются в институциональной среде (организованная преступность, коррупция, теневая экономика и т. д.)» [6, с. 58].

Стоит отметить, что мы обозначили только некоторые примеры причин возникновения институциональных ловушек. Количество работ на эту тему уже измеряется сотнями. Из ныне действующих институциональных ловушек часто приводят классификацию М. Ю. Малкиной, которая выделяет, как минимум, 6 ловушек, мешающих развитию России [7]:

1. Психологическая неготовность общества к инновациям (скептицизм и нигилизм, несклонность к риску и изменениям, отсутствие понимания проблемы и способов ее решения).

2. Ловушки рентоориентированного поведения. Борьба за доступ к сфере извлечения ренты делает первоочередными инвестиции в административный ресурс. Такое поведение, порождая целый комплекс комплементарных институтов, становится устойчивой альтернативой инновационному поведению.

3. Ловушки догоняющего развития и копирования, более эффективные в краткосрочном периоде, чем создание новых технологий. Большинство хозяйствующих субъектов нацелены на удовлетворительный результат, а не на наилучший из возможных, поэтому будут приобретать ресурсы по минимальной цене, пока их использование позволяет им остаться в этой самой зоне удовлетворительности.

4. Нежелание бизнеса инвестировать средства в развитие, вследствие чего происходит недостаточное воспроизводство базы исследований. Инновации связаны с инвестициями в специфические активы, приносящими доход в течение длительного периода времени, в то же время сопряженными с высокими неопределенностью и рисками. Более предпочтительным для отечественного бизнеса оказывается увеличение личного дохода владельцев, сберегательная часть которого расходуется на стандартное портфельное инвестирование с сильно дифференцированным риском. Ярким примером, подтверждающим данное положение, является, на наш взгляд, финансовый кризис на Кипре 2013 г., когда выяснилось, что в депозитной системе этого государства размещены огромные средства не только российского частного бизнеса, но и компаний с государственным участием.

\section{Baikal Research Journal}


5. Ловушки системы общественных финансов, связанные с недостатком эффективности распоряжения указанными средствами.

6. Ловушки имитации инновационной деятельности.

Необходимо также сказать, что многие из авторов в качестве механизмов разворачивания (закрепления) ловушек приводят возникновение сетевых эффектов, рассматриваемых в рамках более общей теории зависимости от предшествующего развития - эффектов сопряжения, координации, обучения, инерции, адаптивных ожиданий, формирующих возрастающую во времени отдачу от функционирования любых (даже неэффективных) институтов.

Представленному подходу можно в какой-то мере противопоставить работы О. С. Сухарева, считающего институциональные ловушки частным случаем проявления дисфункции институтов и подвергающего саму концепцию «ловушки» по отношению к институтам научной критике [8]. Саму критику указанного автора можно сгруппировать по следующим направлениям:

Во-первых, эксперты, использующие термин «институциональная ловушка» под данным явлением, часто рассматривают явления, известные в более общей теории зависимости от предшествующего развития с добавлением также известного «эффекта блокировки». Термин «ловушка» применяется в экономической науке «по иным поводам и основаниям» [Там же, с. 40] - ликвидная, демографическая, мальтузианская, ловушка бедности и т. д. Тем самым создается терминологическая путаница, введение или зачастую неоправданное использование новых определений, ошибки в категорийном анализе.

Во-вторых, любая диспропорция, тормозящая темпы экономического роста и развития в целом (особенно если она носит самоподдерживающий характер), может быть названа «ловушкой». Однако подобную диспропорцию нельзя назвать неэффективной нормой, так как сложившаяся система правил и множества институтов генерирует пускай небольшую, но эффективность. Конечно, можно говорить, что существует некая более рациональная и эффективная структура, состоящая как минимум из нескольких институтов. Поэтому большинство «институциональных ловушек» - по своей природе некий реактивный ответ «на повышение дисфункциональности набора институтов» $[8$, с. 40].

В-третьих, многие авторы совершенно не задумываются, какая норма является эффективной и в чем может проявляться ее неэффективность. Действительно, если агентам выгодно по какой-либо причине не соблюдать «эффективную» норму в пользу нормы-ловушки и это состояние характеризуется устойчивостью и самоподдерживаемым характером - само понятие эффективности размывается и переворачивается с ног на голову. Ведь «если отклониться от нормы выгоднее, как же она может быть эффективнее» [Там же, с. 40]. Мы опять же видим категорийную путаницу и ошибку в разграничениях понятий «эффективность» и «стабильность». В качестве примера приводится коррупционное взаимодействие между агентами. «Если агенты следуют правилам, что связаны с меньшими издержками, (например, коррупционная схема более удобна), то это значит, что легальная схема невозможна или сопряжена с такими издержками, что эффект блокировки имеет обратный знак и не коррупция является «lock in», а наоборот: легальная модель поведения становится невозможной и блокирует такую деятельность, т. е. саму себя, замещаясь иной схемой, правилами» [Там же, с. 41].

B-четвертых, автор обращает внимание на методологические ошибочные предпосылки в анализе многих «институциональных ловушек». Речь идет о не совсем корректном использовании рационалистических критериев эффективности для оценки иррационального агента. Если отклонение от норм «институциональной ловушки» невыгодно и сопряжено с большими затратами, значит оптимальное состо-

\section{Baikal Research Journal}

электронный научный журнал Байкальского государственного университета 
яние связано с еще большими издержками. Если же это не так, то поведение агента становится нерациональным или ограниченно рациональным. Здесь автор задает весьма уместный, на наш взгляд, вопрос: как можно «сугубо рационалистическим критерием измерять нерациональное поведение, иррациональный выбор? Он сразу же будет рассмотрен как неэффективный» [8, с. 41].

Во многом вся эта критика соотносится с негативным отношением многих экономистов к так называемым «гибридным моделям» [9, с. 478-579], в рамках которых происходит изменение некоторых предпосылок неоклассической теории при неизменности тесно с ними связанных остальных:

1. Эти модели неудовлетворительны ввиду того, что они строятся с использованием противоречивых предпосылок. Например, уровень доступности информации для принятия решений часто не согласуется с ограниченной рациональностью и трансакционными издержками.

2. В подобных моделях допускается только рациональный выбор как способ поведения, несмотря на то, что другие методы, сокращая издержки принятия решений и издержки оптимизации, могут давать более предпочтительные результаты.

3. Решения, полученные на основе гибридной модели, формально могут выглядеть правдоподобно, но они являются фундаментально ошибочными, поскольку базируются на совокупности данных и процедурах принятия решений, которые в действительности превосходят возможности реально существующих людей.

В-пятых, О. С. Сухарев отмечает особого рода проблему в выявлении факторов, формирующих институциональные ловушки. Особо отмечается, что к ним относят все больший набор фундаментальных, организационных и социальных факторов, которые «покрывают столь значительную область, что охватывают просто целиком экономическую систему, их конкретизация предполагает отдельную и сложную научную задачу» $[8$, с. 43$]$.

Учитывая изложенное, на наш взгляд, не совсем верно будет утверждать, что низкий уровень адаптивности российской экономики является «институциональной ловушкой», так как в основе любой из рассмотренных ранее ловушек лежат дисфункции многих (как минимум, нескольких) институтов и эффект блокировки, а каждая из этих ловушек оказывает негативное влияние на адаптивную эффективность - более правильно представляется вести речь об адаптивной дисфункции национальной институциональной среды. Следовательно, концентрации на прекращении действия какой-либо нормы или отдельного института совершенно недостаточно для разрешения сложившейся ситуации. Более того, если мы правы, и проблема носит комплексный характер с не до конца выявленными внутренними причинами и связями, начинать нужно с анализа того базиса, который и формирует дисфункциональные состояния.

На наш взгляд, один из наиболее близко подошедших к объяснению фундаментальной неэффективности национальных институтов в целом - Е. Балацкий. Указанный автор опирается на работы Д. Норта, где исследуется дихотомия двух основных функций, выполняемых любыми институтами (создание ограничений и создание стимулов [10, с. 104]), и выводится противоречивость свойств института (жесткость и гибкость [Там же, с. 155]).

Е. Балацкий делает вывод, что «эффективные институты в краткосрочном периоде должны обладать свойством стабильности (жесткости), а в долгосрочном свойством адаптивности (гибкости). Подавляя опасные текущие поведенческие девиации, институты тем не менее должны постоянно эволюционировать под воздействием глобальных технологических сдвигов. При этом система институциональных ограничений ответственна за достижение краткосрочных целей, а система мотивации - долгосрочных» [11, с. 155]. Таким образом, можно сделать вывод, что

\section{Baikal Research Journal}

электронный научный журнал Байкальского государственного университета 
причиной адаптивно-неэффективных институтов (и институциональных ловушек) являются разрушение институциональной мотивации (стимулов) и, как следствие, снижение гибкости всей системы.

Если рассматривать адаптивную эффективность с позиций устойчивых неэффективных институтов и в контексте представленной критики, представляется интересным анализ динамики элементов базового индекса институционального развития, рассчитываемого Е. Балацким и Н. Екимовой, которые отмечают, что «в России за прошедшие годы сложилась довольно своеобразная институциональная модель развития, состоящая в создании достаточно широкого объема политических, социальных и экономических гарантий путем ущемления различных видов свободы. С одной стороны, в России созданы некие базовые гарантии и ограничения, которые, судя по всему, исключают революции и другие серьезные социальные потрясения. С другой стороны, в России сдерживаются внутренние источники развития» $[12$, с. 41$]$. Основные причины сложившегося институционального «провала», по мнению исследователей, лежат в плоскости низкой адекватности сложившимся реалиям со стороны элит и чрезмерного давления со стороны фискальных и кредитных государственных институтов, что лишает российских экономических агентов необходимой свободы и инициативы [Там же, с. 43-44].

Учитывая изложенное, можно, на наш взгляд сказать, что в России сложилась ситуация воспроизводства стабильно-жесткой институциональной среды, нацеленной в большей степени на краткосрочные ограничения, чел на стилулирование изленений. Это, очевидно, и является общей характеристикой дисфункционального состояния российской институциональной среды, препятствующего повышению адаптивной эффективности ${ }^{1}$.

В рамках «дисфункционального» подхода более полно, на наш взгляд, реализуется тезис о неразумности трансформации какого-либо отдельного института для повышения стабильности или адаптивности системы. Действительно, любой институционалист априори предполагает не просто взаимосвязь, но и глубокую интеграцию всех сфер общества (а, соответственно, и институтов) - социальной, экономической, политической, духовной. Однако до сих пор мы наблюдаем попытки активного бездумного заимствования наиболее «эффективных" институтов из различных систем. Например, институты социальных гарантий - из одной страны, стабилизирующие экономические параметры (безработица, инфляция и т. д.) - из других стран, а правила, повышающие гибкость и адаптивность - из третьих.

При этом зачастую не учитывается, что нормы, правила, например экономического характера, интегрированы в жесткий институциональный каркас конкретной системы-донора и, как правило, дисфункциональны по тому или иному признаку в другой структуре. «Авторы пытаются копировать действующие институты передовых стран, не учитывая имеющиеся культурные, институциональные, ресурсные и технологические ограничения; игнорируют опыт развития соответствующих институциональных подсистем» [13, с. 72]. В сложившейся ситуации борьба с отдельными институциональными ловушками не просто не приносит результатов, но и зачастую усугубляет ситуацию. Все это ставит под сомнение у многих реформаторов рациональность использования «мирового опыта». С другой стороны, поиск отдельных национальных институтов путем социального экспериментирования опять же ведет к дисфункциям и ухудшению состояния.

\footnotetext{
${ }^{1}$ Вообще, на наш взгляд, синтезируя оба подхода, можно вести речь о «дисфункциональной ловушке» в том плане, что сложившееся в целом состояние институциональной системы препятствует росту адаптивной эффективности национальной экономики.
}

\section{Baikal Research Journal}


В результате мы видим целый ряд «институциональных ловушек», образующих уже самый настоящий кластер, которому характерны не просто стабильность и самоподдержание, но и расширенное воспроизводство. Возможно, следует отказаться от бездумных моделей и рекомендаций трансформации отдельных норм, формирующих «институциональные ловушки», как от процесса, не имеющего ни научного, ни институционального основания, так как по большей части мы имеем дело с дисфункцией институциональной системы (в крайнем случае, ее агрегированных частей), а не отдельного элемента. Следует также учитывать тот факт, что за то время, пока мы боремся с отдельными неэффективными нормами, под влиянием «эффекта блокировки» возрастает общая дисфункциональность институциональной среды, которой и следует заниматься в первую очередь.

Учитывая изложенное, считаем, что для повышения адаптивной эффективности национальной экономики совершенно недостаточно внедрение элементов конкуренции, децентрализации и защиты прав собственности в экономической сфере. Недостаточными также представляются попытки преодоления отдельных «институциональных ловушек». Проблема стоит гораздо шире, и для ее решения необходим ряд фундаментальных сдвигов в самом понимании проблемы, среди которых особо хотелось бы выделить следующее: необходимо не просто осознание несоответствия сложившейся социально-экономической системы национальным интересам и не просто "ретуширование» и подгонка ее отдельных элементов, но и четкое понимание той структуры, к которой мы хотим прийти. Речь в данном случае идет не столько о несомненно необходимом «проектировании процесса реформ» [14], сколько о тех конечных параметрах, к которым мы стремимся. Иначе велика вероятность внедрения противоречащих и взаимоисключающих друг друга институтов. Вообще нам, мягко говоря, не до конца понятна позиция многих специалистов, занимающихся макроэкономической политикой, согласно которой неявно предполагается возможным (пускай даже теоретически) максимизация полезных эффектов одновременно в разных группах институтов (социальных, экономических, политических).

Намного более правильной представляется точка зрения о принципиальной разнице не просто институтов, а самих институциональных моделей на примере «англосаксонской институциональной модели развития с акцентом на предоставление максимальной свободы и континентальной европейской модели с акцентом на построение базовых гарантий" [12, с. 42]. Таким образом речь идет о том, что общество и государство должны сделать осознанный выбор, по какому пути двигаться: пытаться и дальше развиваться по логике континентальной модели с некоторым будущим поэтапным увеличением свобод (которые никогда даже теоретически не достигнут в рамках этой модели «либерального идеала»), либо в очередной раз пройти через «шоковую» социальную трансформацию и попытаться переключиться на англосаксонскую модель. Именно от результатов этого выбора и будет во многом зависеть та структура и направленность институтов, которые необходимо развивать для повышения адаптивной эффективности.

Для англасаксонской модели, на наш взгляд, более характерна система «автономной» адаптации по О. Уильямсону [15, с. 281] с ее упором на рыночное (стихийное) регулирование. В данном случае адаптивно-эффективная структура, видимо, будет опираться на институты, максимально нацеленные на развитие ранее перечисленных макрофакторов по Д. Норту.

Континентальная же модель наиболее соответствует «скоординированной» адаптации по О. Уильямсону [15, с. 281] с ее упором на иерархичное (сознательное) регулирование. При таком подходе особая роль должна отводиться развитию и усилению институтов макроэкономической промышленной политики.

\section{Baikal Research Journal}

электронный научный журнал Байкальского государственного университета 
По ряду причин считаем более оптимальным формирование континентальной модели.

Во-первых, велик риск того, что сил и ресурсов пережить очередной шок у России просто не хватит. Так, например, С. В. Чупров, рассматривая ситуацию возможных масштабных институциональных преобразований, отмечает, что «на фоне сильно возмущенного мирового экономического пространства синхронное наложение этих тенденций способно инициировать резонирующий эффект с тяжелыми последствиями для индустриализации РФ. При таком сценарии глобализация обернется для промышленности России укоренением в ней пагубных процессов и отбросит ее еще дальше в разряд стран-аутсайдеров... Нечего и говорить, что исходящий из-за границы неконтролируемый поток проникающих помех способен надорвать и без того ослабленную шоковой либерализацией отечественную индустрию» [16].

Во-вторых, обширные территории, климатические условия, географическая неоднородность создают объективные потребности в стимулировании и координации экономического развития, что без активной роли государства весьма проблематично. В этом плане интересен пример Китая, реализующего, например, модель крупномасштабных инвестиций под руководством и с учетом государственной стратегии. «Поскольку при таких инвестициях необходимы крупные суммы, срок окупаемости инвестиций весьма длителен, риски велики, то здесь необходима поддержка правительства и взятия им риска на себя. Типичными представителями данной модели являются три крупные нефтяные компании - «Петрочайна», «Синопек» и «Китайская компания морской добычи нефти» $[17$, с. 84].

B-третьих, как показывает исторический опыт, этап догоняющего развития (на котором сейчас находится Россия) во всем мире проходил при активной промышленной политике. Даже более того, в наиболее развитых странах поддержка крупного национального бизнеса (с помощью налоговой политики, защиты от внешних конкурентов, участия в промышленном шпионаже и управления научно-техническим прогрессом) на сегодняшний день является одной из целей макроэкономической политики, что приводит многих экспертов к выводу: «государства в развитых странах в XXI в. становятся все более активными и равноправными участниками экономических процессов, происходящих в рамках национальных экономик и в мировом хозяйстве, так что развивающимся странам не следует при проведении даже самых радикальных рыночных реформ выполнять все указания США по сокращению государственного присутствия в экономике» [18].

В-четвертых, многонациональный уклад и исторически сложившаяся система неформальных институтов сформировала в большинстве российского населения тягу к редистрибуции ${ }^{2}$, коллективизму (общинности), координационным (а не конкурентным) механизмам взаимодействия и порядку (даже в ущерб личным свободам) [19]. Как мы понимаем, подобного рода черты больше соответствуют континентальной модели, а значит конфликт между формальными и неформальными институтами может быть минимизирован.

Понятно, что более вероятно формирование некой гибридной формы, но даже в ее рамках необходимо, как нам кажется, доминирование одного из вариантов, хотя бы из соображений избежать повышенных рисков дисфункциональности всей системы (ввиду противоречивости многих институтов, характерных для разных моделей) и для более полного приобретения преимуществ от «специализации» адаптивной эффективности (как и многие институционалисты, мы

${ }^{2}$ Сущность редустрибутивных экономик - обязательное опосредование неким Центром движения ценностей и услуг, а также права по их производству и использованию.

\section{Baikal Research Journal}


все-таки придерживаемся принципа дихотомий «рынок-иерархия» и «стихийное-сознательное»).

Однако как мы можем наблюдать в действительности, окончательный выбор ни одного из вариантов еще не сделан. Это подтверждается тем, что инструментарий государственного экономического управления используется преимущественно либерально-неоклассический (с одновременным внедрением соответствующих институтов), а институциональная модель России носит ярко выраженный континентальный характер.

\section{Список использованной литературы}

1. Норт Д. Институты, институциональные изменения и функционирование экономики / Д. Норт ; пер. с англ. А. Н. Нестеренко ; под ред. Б. З. Мильнера. - М. : Начала, 1997. $-178 \mathrm{c}$.

2. Полтерович В. М. Институциональные ловушки - результат неверной стратегии реформ / В. М. Полтерович // Экономическая наука современной России. — 1998. - (Приложение. - С. 22-28).

3. Сухарев О. С. Институциональное планирование экономического развития: проблема эффективности / О. С. Сухарев // Журнал экономической теории. - 2005. — № 3. - С. 52-70.

4. Беренделева Е. B. QWERTY-эффекты, институциональные ловушки с точки зрения теории трансакционных издержек / Е. В. Беренделева // Экономический вестник Ростовского государственного университета. - 2006. - Т. 4, № 2. - С. 42-47.

5. Абелян А. С. Россия, модернизация экономики и институциональные ловушки: структурные и институциональные императивы модернизации экономики России / А. С. Абелян, Ф. Э. Аксаев // Российское предпринимательство. — 2010. — № 8-2. — С. 13-19.

6. Лысенко Ю. Современная парадигма институциональных ловушек / Ю. Лысенко, А. Стрижак // Журнал экономической теории. - 2014. - Т. 11, № 4. - С. 48-61.

7. Малкина М. Ю. Институциональные ловушки инновационного развития российской экономики / М. Ю. Малкина // Journal of Instutional Studies. - 2011. - T. 3, № 1. - С. 50-60.

8. Сухарев О. С. Новый институционализм: «ловушки», трансакционные издержки, «теорема Коуза» и время / О. С. Сухарев // Terra Economicus. — 2012. — T. 10, № 3. - С. 39-57.

9. Фуруботн Э. Г. Институты и экономическая теория: достижения новой институциональной экономической теории : пер. с анг. / Э. Г. Фуруботн, Р. Рихтер ; под ред. В. С. Катькало, Н. П. Дроздовой. - СПб. : Изд-во С.-Петерб. гос. ун-та, 2005. - 736 с.

10. Норт Д. Понимание процесса экономических изменений / Д. Норт. - М. : Изд. дом ВШЭ, 2010. - 256 с.

11. Балацкий Е. В. Когнитивно-институциональный синтез Д. Норта / Е. В. Балацкий // Общественные науки и современность. - 2011. — № 5. - С. 154-166.

12. Балацкий Е. В. Эффективность институционального развития России: альтернативная оценка / Е. В. Балацкий, Н. А. Екимова // Terra Economicus. - 2015. — T. 13, № 4. — C. 31-51.

13. Полтерович В. М. Почему реформы терпят неудачу / В. М. Полтерович // Журнал Новой экономической ассоциации. - 2014. - № 3. - С. 169-173.

14. Полтерович В. М. Промышленная политика: рецепты или институты? / В. М. Полтерович // Журнал Новой экономической ассоциации. - 2014. — № 2 (22). — С. 190-195.

15. Williamson O. E. Comparative Economic Organization: The Analysis of Discrete Structural Alternatives / O. E. Williamson // Administrative Science Quarterly. - 1991. _ Vol. 36. P. 269-296.

16. Чупров С. В. Неустойчивое развитие - реалия глобализации и императив индустриализации российской экономики [Электронный ресурс] / С. В. Чупров // Известия Иркутской государственной экономической академии (Байкальский государственный университет экономики и права). — 2014. - № 5. - Режим доступа : http://brj-bguep.ru/reader/article. aspx?id=19420.

17. Цвигун И. В. Формирование китайских транснациональных корпораций на основе государственной стратегии «выхода за границу» / И. В. Цвигун, Мэн Дэмин. - Иркутск : Изд-во БГУЭП, 2010. - 148 с.

\section{Baikal Research Journal}

электронный научный журнал Байкальского государственного университета 
18. Макарова Г. Н. Государственная поддержка крупного предпринимательства - реальность экономической политики развитых стран в XXI в. [Электронный ресурс] / Г. Н. Макарова // Известия Иркутской государственной экономической академии (Байкальский государственный университет экономики и права). - 2012. - № 2. - Режим доступа : http:// brj-bguep.ru/reader/article.aspx $\mathbf{i d}=12260$.

19. Кирдина С. Г. Теория институциональных матриц / С. Г. Кирдина // Постсоветсткий институционализм / под ред. Р. М. Нуреева, В. В. Дементьева. - Донецк : Каштан, 2005. C. $75-101$.

\section{References}

1. North Douglass. Institutional Change and Economic Performance. Cambridge University Press, 1990. 159 p. (Russ. ed.: North D. Instituty, institutsionalnye izmeneniya i funktsionirovanie ekonomiki. Moscow, Nachala Publ., 1997. 178 p.).

2. Polterovich V. M. Institutional traps as a result of wrong reform strategy. Ekonomicheskaya nauka sovremennoi Rossii = Economic Science of Modern Russia, 1998, pp. 22-28. (In Russian).

3. Sukharev O. S. Institutional planning of economic development: efficiency problem. Zhur nal ekonomicheskoi teorii = Journal of Economic Theory, 2005, no. 3, pp. 52-70. (In Russian).

4. Berendeleva E. V. QWERTY-effects, institutional traps from the point of transaction costs theory. Ekonomicheskii vestnik Rostovskogo gosudarstvennogo universiteta = Economic Herald of Rostov State University, 2006, vol. 4, no. 2, pp. 42-47. (In Russian).

5. Abelyan A. S., Aksayev F. E. Structural and Institutional Imperatives of Modernization of the Russian Economy. Rossiiskoe predprinimatel'stvo = Russian Entrepreneurship, 2010, no. 8-2, pp. 13-19. (In Russian).

6. Lysenko Yu., Strizhak A. Modern paradigm of institutional traps. Zhurnal ekonomicheskoi teorii = Journal of Economic Theory, 2014, vol. 11, no. 4, pp. 48-61. (In Russian).

7. Malkina M. Yu. Institutional traps of innovative development of Russian economy. Jour nal of Instutional Studies, 2011, vol. 3, no. 1, pp. 50-60. (In Russian).

8. Sukharev O. S. New institutionalism: «traps», transaction costs, «Coase theorem» and time. Terra Economicus, 2012, vol. 10, no. 3, pp. 39-57. (In Russian).

9. Furubotn Eirik G., Richterand Rudolf. Institutions and Economic Theory. Contribution of New Institutional Economics. The University of Michigan Press, 1998. 542 p (Russ. ed.: Furubotn E. G., Richter R.; Kat'kalo V. S., Drozdova N. P. (eds). Instituty i ekonomicheskaya teoriya: dostizheniya novoi institutsional'noi ekonomicheskoi teorii. Saint Petersburg State University Publ., 2005. 736 p.).

10. North Douglass. Understanding the Process of Economic Changes. Princeton University Press, 2005, 187 p. (Russ. ed.: North D. Ponimanie protsessa ekonomicheskikh izmenenii. Moscow, Higher School of Economics Publ., 2010. 256 p.).

11. Balatsky E. V. Cognitive-institutional synthesis of D. Norts. Obshchestvennye nauki $i$ souremennost' = Social Sciences and the Present, 2011, no. 5, pp. 154-166. (In Russian).

12. Balatsky E. V., Ekimova N. A. Effectiveness of Russian institutional development: an alternative assessment. Terra Economicus, 2015, vol. 13, no. 4, pp. 31-51. (In Russian).

13. Polterovich V. M. Why Do Reforms Fail. Zhurnal Novoy ekonomicheskoy assotsiatsii= Journal of New Economic Association, 2014, no. 3, pp. 169-173. (In Russian).

14. Polterovich V. M. Industrial Policy: Recipes or Institutions? Zhurnal Novoy ekonomicheskoy assotsiatsii = Journal of New Economic Association, 2014, no. 2 (22), pp. 190-195. (In Russian).

15. Williamson O. E. Comparative Economic Organization: The Analysis of Discrete Structural Alternatives. Administrative Science Quarterly, 1991, vol. 36, pp. 269-296.

16. Chuprov S. V. Unsustainable development - a globalization realia and an imperative of Russian economic industrialization. Izvestiya Irkutskoy gosudarstvennoy ekonomicheskoy akademii (Baykalskiy gosudarstvennyy universitet ekonomiki i prava) = Bulletin of Irkutsk State Economics Academy (Baikal State University of Economics and Law), 2014, no. 5. Available at: http://brj-bguep.ru/reader/article.aspx?id=19420. (In Russian).

17. Tsvigun I. V., Men Demin. Formirovanie kitaiskikh transnatsio-nal'nykh korporatsii na osnove gosudarstvennoi strategii «vykhoda za granitsu» [Development of Chinese transnational

\section{Baikal Research Journal}


corporations on the basis of state strategy «outflow over the border», Irkutsk, Baikal State University of Economics and Law Publ., 2010. 148 p.

18. Makarova G. N. Government support of large business - reality of economic policy of the developed countries in the XXI century. Izvestiya Irkutskoy gosudarstvennoy ekonomicheskoy akademii (Baykalskiy gosudarstvennyy universitet ekonomiki i prava) = Bulletin of Irkutsk State Economics Academy (Baikal State University of Economics and Law), 2012, no. 2. Available at: http://brj-bguep.ru/reader/article.aspx?id=12260. (In Russian).

19. Kirdina S. G. Theory of institutional matrixes. In Nureyev R. M., Dementyev V. V. (eds). Postsovetstkii institutsionalizm [Post-Soviet institutionalism]. Donetsk, Kashtan Publ., 2005, pp. 75-101. (In Russian).

\section{Информация об авторе}

Рудяков Василий Анатольевич - кандидат экономических наук, докторант, кафедра экономической теории и институциональной экономики, Байкальский государственный университет, 664003, г. Иркутск, ул. Ленина, 11, e-mail: fmened@mail.ru.

\section{Author}

Vasiliy A. Rudyakov - PhD in Economics, Doctoral Student, Chair of Economic Theory and Institutional Economics, Baikal State University, 11 Lenin St., 664003, Irkutsk, Russian Federation; e-mail: fmened@mail.ru.

\section{Библиографическое описание статьи}

Рудяков В. А. Падение адаптивной эффективности российской экономики - институциональная ловушка или дисфункциональное состояние? / В. А. Рудяков // Baikal Research Journal. - 2016. — T. 7, № 2. — DOI : 10.17150/2411-6262.2016.7(2).1.

\section{Reference to article}

Rudyakov V. A. Decline of adaptive efficiency of Russian economy - is it an institutional trap or a dysfunctional state? Baikal Research Journal, 2016, vol. 7, no. 2. DOI: 10.17150/24116262.2016.7(2).1. (In Russian).

\section{Baikal Research Journal}

